\title{
A Trama de Memória Inscrita no Corpo
}

MERLINO, Maria Lúcia (bolsista Fapesp)

QUILICI, Cassiano Sydow (co-autor)

Somos nossa memória, somos esse quimérico museu de formas inconstantes, esse montão de espelhos rompidos. Jorge Luiz Borges 
Introdução

As práticas da educação somática ${ }^{1}$ privilegiam a experiência subjetiva da corporeidade, constituindo-se como um campo de conhecimento relativamente recente, ainda em processo de construção. Apesar de muitas destas práticas utilizarem em sua base o conhecimento anatômico e neuro-fisiológico, elas não operam com formas de leitura e intervenção num corpo que é observado "de fora". O termo 'somática' foi cunhado pelo filósofo Thomas Hanna (in Johnson, 1995), para definir o fenômeno do corpo humano a partir do ponto de vista dos sentidos proprioceptivos, ou seja, do corpo percebido em "primeira-pessoa", de "dentro para fora". Alguns teóricos e educadores somáticos têm desenvolvido também uma reflexão sobre os aspectos sociais e culturais implicados nas questões corporais ${ }^{2}$. De certa forma, tais práticas têm inventado seus procedimentos a partir da ampliação das abordagens filosóficas, científicas e culturais sobre o tema, que se intensificaram nas últimas décadas.

A Integração Estrutural - Rolfing é um sistema de reeducação postural e do movimento que apresenta uma abordagem sistêmica e que está inserida no campo somático. Através de uma série de manipulações, desencadeiam-se alterações estruturais e funcionais do sistema músculo-esquelético, mudanças na percepção e na sensação processadas no corpo, podendo desencadear alterações significativas no relacionamento do sujeito com o ambiente, e nas suas relações consigo mesmo e com os outros.

A reeducação promovida através do Rolfing é adquirida através de uma "experiência" corporal singular, em que podem emergir novas formas de apreensão e representações mentais. Neste caminho, a pessoa pode ampliar sua percepção, recriando as imagens internas de si mesma e de certos padrões de relação. Entendemos que a transformação dessas novas percepções em "metáforas", formuladas em palavras e imagens a partir das experiências vividas no tratamento, tem também uma importante função terapêutica. Nesta direção, pensaremos o Rolfing aqui como um método em que a pessoa pode reorganizar, através de uma série de estratégias, a trama de memória inscrita no corpo.

\section{O que é Integração Estrutural-Rolfing?}

Do ponto de vista somático, o Rolfing pode ser pensado
1.

Envolvendo métodos sofisticados de toque, movimento e consciência corporal, as escolas de abordagem somática se desenvolvem fora dos meios acadêmicos e incluem métodos como Rolfing, Feldenkrais, Técnica de Alexander, Body Mind Centering, Eutonia, Continuum, Terapia Cranio Sacral, Movimento Autêntico, para citar apenas algumas. O sucesso destas práticas está no fato de que podem ser bem sucedidas em aliviar diversos sintomas de problemas crônicos, impermeáveis às estratégias terapêuticas convencionais. Alguns destes métodos estão sendo utilizados como complementares em tratamentos convencionais, como o Rolfing, presente como terapia complementar no Programa de Reabilitação da Fisioterapia do Hospital Albert Einstein em São paulo.

2. É o caso de Hubert Godard (2013), para quem nossa experiência do soma é influenciada pela interação com o ambiente que nos cerca e pela maneira como compreendemos a nós mesmos e o mundo através do corpo. A maneira que damos sentido ao mundo estaria intimamente relacionada às nossas experiências somáticas. 
como um método de desenvolvimento da consciência corporal a partir de um reaprendizado da escuta do próprio organismo. Ida Rolf3 (apud Feitis, 1994) dizia que os praticantes da Integração Estrutural-Rolfing eram educadores - e por isso, neste artigo, as pessoas que passam pelo método serão chamadas de "alunas", ao invés de clientes ou pacientes.

Em geral, a educação convencional tem o efeito de imprimir uma desconexão fundamental entre pensamento e experiência. Essa cisão tende a diminuir a consciência que temos dos processos corporais envolvidos nas nossas relações diárias. É comum que incorporemos hábitos nocivos que se agregam diariamente em nossas experiências de respiração, tensão, movimento e postura. Para tratar desses automatismos é necessário uma "técnica" que não seja praticada como uma nova forma de adestramento mas como uma "arte". De acordo com Larrosa:

\begin{abstract}
... nos modos dominantes de racionalidade, não há logos de experiência, não há razão de experiência, não há linguagem da experiência, mesmo que essas formas de racionalidade façam uso e abuso da palavra experiência.(...) Então a primeira coisa a fazer, me parece, é dignificar a experiência, reivindicar a experiência, e isso supõe dignificar e reivindicar tudo aquilo que tanto a filosofia quanto a ciência tradicionalmente menosprezam e rejeitam: a subjetividade, a incerteza, o provisório, o corpo, a fugacidade, a finitude, a vida ... (2004, p.22).
\end{abstract}

Faz parte do processo do Rolfing reorganizar as redes fasciais ${ }^{4}$ do corpo humano, através de um toque específico no tecido miofascial, soltando padrões habituais de tensão. Organizada tradicionalmente em dez encontros, esta série tem um efeito cumulativo de sessão a sessão, já que cada uma delas produz uma onda de mudança na rede miofascial, afetando todos os sistemas orgânicos simultaneamente. Qualquer mudança estrutural no corpo requer um período de reaprendizagem e de integração, e estas mudanças vão exigir uma adaptação no sistema sensóriomotor. O corpo vai sentir diferente, e haverá possibilidade de ocorrer também novos padrões de recrutamento muscular. Entretanto, se não "dignificarmos a experiência", como diz Larrossa, tais sensações serão descartadas. O processo do Rolfing vai ajudar, portanto, a construir novas coerências internas, reconhecer essas novas coerências, e se apropriar dessas novas coerências.

O pesquisador Hubert Godard 5 (2010), um importante cola-
3.

Ida P. Rolf (1896-1979) é a criadora do método Integração Estrutural-Rolfing. Nascida em Nova York, formou-se em Bioquímica, tornando-se uma das principais pesquisadoras do Rockfeller Institute, um grande feito para uma mulher jovem no início do século XX. Recebeu o título de Ph.D em Química Biológica pela Universidade de Columbia em 1920. Estudou Matemática e Física Atômica na Universidade Técnica Suíça, em Zurique, e Medicina Homeopática em Genebra, além de aprofundar seus estudos em Medicina Quiroprática, Osteopatia, ioga e outras técnicas. A partir dos anos quarenta, e pelo resto de sua vida, dedicou-se a desenvolver o método que viria a ser conhecido como INTEGRAÇÃO ESTRUTURAL - ROLFING ${ }^{\circledR} \mathrm{e}$ seu programa de treinamento.

4.

A rede fascial pode ser definida como o conjunto de tecido conjuntivo fibroelástico, muito extenso, contínuo em todo o corpo. A fáscia envolve e penetra nos músculos e em todas as outras estruturas do corpo. Cada fáscia, de cada músculo, envolve e separa músculos diferentes em compartimentos. Ela envolve e compartimenta os órgãos, encapsula nervos e vasos, envolve os órgãos torácicos e pélvicos. Faz a pleura, pericárdio e peritônio. A fáscia liga osso ao osso, músculo a osso, e forma as bandas tendíneas. 
borador para o desenvolvimento do Rolfing, realçou a relevância da singularidade da percepção da pessoa no contexto do ambiente, na construção do equilíbrio e da coordenação. A fluidez do movimento seria a resposta desejável para um corpo que está em harmonia com as forças do campo gravitacional e que tem pleno potencial de ação em todas as direções do movimento possível. Essa boa capacidade de resposta sinaliza, segundo Godard, pleno "potencial de ação" da pessoa.

Para outro importante pesquisador dessa área, o filósofo Jeffrey Maitland (1996), Rolf desenvolveu uma fenomenologia prática, uma ciência e uma filosofia ancoradas na realidade psico-física do ser humano: sua escola de pensamento provê um modo poderoso e sistemático de provocar mudanças significativas na vida das pessoas através da transformação dos seus corpos.

Quando o Rolfing se torna uma experiência singular, faz reconhecer a importância das sensações somáticas como um guia para nossas ações. A questão aqui é que não conseguiremos "soltar nossos ombros", por exemplo, se não temos a capacidade de sentir que nossos ombros estão tensos, ou se não sabemos como é a sensação de termos os ombros soltos. Não conseguimos abandonar nossa máscara facial se não conhecemos a sensação de estarmos sem a máscara. A maioria de nós acaba por adotar posturas inadequadas sem se dar conta disso. Através de processos de aprendizagem envolvendo a atenção sensível às nossas sensações proprioceptivas desenvolvemos a habilidade de reconhecer e evitar uma rigidez desnecessária, um colapso interno, ou uma compressão de achatamento, na nossa atitude corporal. O que o Rolfing faz num primeiro momento, como todo método de educação somática, é promover o auto-reconhecimento destes padrões inconscientes de tensão.

Corpo e mundo

A palavra propriocepção vem do latim proprio - de si mesmo, e ceptive - receber. A propriocepção é a maior fonte de informação no que diz respeito ao posicionamento do corpo e à manutenção da postura. O termo propriocepção é usado para descrever a consciência da posição ou do movimento corporal, e envolve tanto a sensação da posição corporal com respeito à gravidade quanto à relação de posição entre suas diversas partes.

A propriocepção é um dos elementos constitutivos da "imagem corporal", que pode ser definida como um complexo conjunto de percepções, representações mentais, crenças e
5

Hubert Godard (1945-) é um pesquisador de movimento francês, que representa a segunda geração do pensamento da escola de Integração EstruturalRolfing. Graduou-se em Química, mas logo foi atraído pela dança e pela qualidade do movimento humano no espaço, desenvolvendo estudos nas áreas da Osteopatia, Feldenkrais, Técnica de Alexander, Método Mézières, entre outros. Foi no treinamento de Rolfing que Godard teve confirmada sua visão de movimento e sua relação com a gravidade, que integrava todos os seus outros estudos. Ao mesmo tempo, foi convidado para uma cadeira na Universidade de Paris, para desenvolver e organizar o ensino da dança na França. Costuma dar aulas para integradores estruturais em vários países, e esteve particularmente presente no Brasil durante a década de 2000. Sua nova teoria sobre Função Háptica e Função Fórica ainda está por ser descrita. 
atitudes, cujo referente é o próprio corpo. Assim, a consciência proprioceptiva é uma experiência sentida do posicionamento corporal, que ajuda a constituir o aspecto perceptual da imagem corporal. Aspectos sociais, culturais e emocionais podem afetar a imagem corporal, provocando distorções e patologias, como a anorexia, a bulimia e a obesidade.

A imagem corporal pode ser compreendida a partir das relações que a pessoa estabelece com o "mundo". Nesse sentido, o ambiente deixa de ser entendido apenas como um espaço "físico" ou "neutro", ao redor do corpo, mas pode ser experimentado de múltiplas formas, como por exemplo um lugar que convida à ação ou, ao contrário, pressiona e reprime. Um possível retrato de uma pessoa deprimida é de alguém com ombros apertados e caídos, cabeça e olhar baixos, peito afundado, andar pesado e lento, curvado pela pressão do mundo que o empurra para baixo. Nesse sentido, mundo é uma construção constante que se dá na relação que se estabelece com circunstâncias em mutação. Deve-se considerar, no entanto, que vão se formando padrões de interação que podem se enrijecer, mantendo-se inconscientes para a pessoa.

A experiência perceptual do corpo alimentada pelos sentidos, por exemplo, é parte integrante da imagem corporal, que vai compor a atitude corporal, a postura corporal do indivíduo. Como manter um equilíbrio corporal quando esses sentidos são embrutecidos por um ambiente cultural marcado pelo excesso de estímulos e pela aceleração das vivências, que em geral dificultam o processo de elaboração das experiências?

A arquitetura da memória no corpo vivido

Damásio (2004) observa que quando o organismo enfrenta uma situação caótica e luta para alcançar o equilíbrio, isso é frequentemente traduzido num sentimento de ausência de prazer e por variedades de dor. Segundo Damásio, os "mapas"6 ligados à alegria significam estados de equilíbrio para o organismo. Refletem uma coordenação fisiológica com bem-estar e são também caracterizados por uma maior capacidade de agir. Os mapas relacionados com a mágoa (Damásio empresta de Espinosa uma definição de mágoa que inclui angústia, medo, culpa, desespero) estão associados a estados de desequilíbrio funcional, onde a facilidade de ação se reduz, com a presença de dor, sinais de doença ou de desacordo fisiológico, indicando uma coordenação diminuída das funções vitais. Se a mágoa não é trabalhada, o organismo se enfraquece e podem seguir-se a doença e a morte.

Damasio descreve o que chama de "arquitetura da memória" como a capacidade do nosso cérebro de fazer regis-
6.

Segundo Damásio (2011) a característica distintiva de um cérebro humano é sua habilidade de criar mapas, para informar a si mesmo. Esses mapas são construídos de fora para dentro, quando interagimos com o mundo, e também evocando nosso banco de memória. A consequência do mapeamento incessante e dinâmico do cérebro é a mente: os padrões mapeados constitutem 0 que conhecemos como sons, visões, cheiros, sensações táteis, sensações proprioceptivas, gostos, dores, prazeres - imagens, na definição de Damásio. As imagens seriam, portanto, os mapas momentâneos que o cérebro cria de todas as coisas, dentro ou fora do corpo. 
tros de visões, sons, sensações táteis, odores e percepções emocionais de um evento a ser lembrado. Com o tempo e a imaginação, a evocação direta poderá perder a intensidade e assim ser recombinada, enfeitada, recortada, transformada. A memória, portanto, seria a maneira como o organismo interage com objetos e eventos, e como o cérebro registra as várias consequências das interações do organismo com o mundo. De acordo com Damásio:

O que memorizamos do nosso encontro com determinado objeto não é só sua estrutura visual mapeada nas imagens ópticas da retina. Os aspectos a seguir também são necessários: primeiro, os padrões sensitivo-motores associados à visão do objeto (como os movimentos dos olhos e pescoço ou o movimento do corpo inteiro, quando for o caso); segundo, o padrão sensitivo-motor associado a tocar e manipular o objeto (se for o caso); terceiro, o padrão sensitivo-motor resultante da evocação de memórias previamente adquiridas relacionadas ao objeto; quarto, os padrões sensitivo-motores relacionados ao desencadeamento de emoções e sentimentos associados ao objeto. O que normalmente denominamos memória de um objeto é a memória composta das atividades sensitivas e motoras relacionadas à interação entre o organismo e o objeto durante dado tempo. (2011, p 169)

É interessante notar como Damásio explicita a relação da memória com o corpo. A memória se constitui a partir das interações entre corpo e objeto, através das sensações cinestésicas. A evocação da memória pode se dar também a partir de qualquer parte que componha um evento: um som, uma visão, um cheiro, um toque.

Vamos acrescentar aqui o padrão de orientação do corpo em relação à gravidade, como um elemento constituído pela rede de memória, fruto dos encontros do corpo com o mundo. Se nossas memórias são organizadas a partir de um conhecimento prévio de objetos comparáveis ou situações semelhantes, são memórias, no dizer de Damásio, preconceituadas pela nossa história e por nossas crenças. A memória inclui fundamentalmente nosso passado, o passado de nossa espécie biológica e de nossa cultura.

Como afirma Bergson (2006), "pensamos apenas com uma pequena parte de nosso passado, mas é com nosso passado inteiro que desejamos, queremos, agimos." Segue dizendo que as lembranças pessoais constituem o mais amplo invólucro de nossa memória, e que se materializam por acaso, por uma determinação acidental precisa de nossa postura corporal, por exemplo.

Assim como nos processos de criação artística relatados por Leonardelli (2008), também no processo do Rolfing, a relação do sujeito com o tempo é não-linear, isto é, não existe apenas 
numa perspectiva cronológica. A trama tecida pelos acontecimentos do passado está inscrita no corpo, e quando essa trama é reorganizada, algumas memórias são evocadas, às vezes de forma consciente, através do fluxo de imagens, outras vezes de modo inconsciente, através do fluxo de emoções que o sujeito não consegue explicar racionalmente.

Esta trama de tecido corporal está se refazendo de modo contínuo, em cada experiência. Esta memória se recria a cada dia. Se a memória não é mais tomada como o retorno do sujeito ao passado, e sim como atualização do vivido no presente, pelas condições do presente, então a narrativa do sujeito torna-se a história pessoal recriada e delineada pelas especificidades técnicas de cada processo. (Leonardelli, 2008, p8).

Um exemplo dessa recriação através da memória no corpo aconteceu numa sessão de Rolfing com uma velha senhora, secretária aposentada. Ao ser tocada nos ombros, ela reviveu a memória da mãe, que costumava amarrar seus ombros à cadeira, para que suas costas não ficassem arqueadas, mantendo o que ela julgava ser uma boa postura. Repentinamente, essa memória encarnada surgiu como trama no tecido, a partir do toque e do que este toque provocou: uma reorganização do corpo todo, através da liberação do tecido da área dos ombros. A evocação da memória dos ombros enrijecidos, composta por um comando de contenção, tensão e repressão foi posta em cheque, cinquenta anos depois, como se fosse... agora. E é exatamente esse fluxo de rede de memória e de tecido que pode ser transformado, reorganizado no corpo.

\section{As sessões de Rolfing}

Se alguém procura ajuda através do Rolfing, está trazendo um desejo de mudança, uma insatisfação, uma dor. Uma entrevista é o primeiro encontro entre aluno e terapeuta, sendo utilizada para levantar estas questões. O aluno narra sua história e o terapeuta registra também o recorte escolhido pelo aluno para esta narrativa. Alguns focam seus relatos apenas na história da dor física que estão trazendo. Outros preferem fazer uma espécie de resumo da história de vida e de experiências existenciais. Muitos relatam, de uma maneira ou de outra, uma sensação de aprisionamento dentro do corpo, um não-saber-lidar com a própria corporeidade. "Não sei o que fazer com minha postura ruim", "não sei o que fazer com meu corpo, odeio essa perna que fica doendo", "não entendo porque dói", "não consigo corrigir minhas costas curvadas, apesar de tentar, eu sempre volto a ficar corcunda" - são frases frequentes nas narrativas dos alunos 
A interação entre aluno e ambiente terapêutico joga um papel importante no atendimento. Quando um número cada vez maior de pessoas vive grande parte do tempo num estado de anestesia e embrutecimento, decorrentes de certo ambiente cultural e social, é necessária a criação de um lugar de acolhimento e calma para estimular a emergência de um novo "sentir". Uma atmosfera de cuidado e atenção reforça a segurança e o bem-estar do aluno, já que os sistemas sensoriais exteroceptivos ${ }^{7}$ mantém o cérebro constantemente informado a respeito do mundo que nos cerca.

Pequenos detalhes como iluminação, cores, temperatura, espaço, som podem ser fatores que causam estresse, se não são bem cuidados, afetando tanto o aluno como o terapeuta. Iluminação direta, sala ruidosa, muito calor ou muito frio, cores berrantes, cheiros muito intensos ou desagradáveis desestabilizam o atendimento. Regularidade nos horários, limpeza, claridade, silêncio, tudo isso contribui para a criação da qualidade do ambiente, tornando possível o desabrochar de um bom vínculo entre aluno-terapeuta, preservando-se e valorizando-se a atenção e a escuta.

À medida que as sessões de Rolfing propõem novas experiências e percepções, deve-se também acolher os relatos e narrativas destas vivências, para que elas possam ser melhor assimiladas Muitas vezes, durante as sessões, os alunos são surpreendidos por devaneios e reminiscências muito antigas, lembranças do tempo da infância. Às vezes, conseguem relacionar essas imagens e emoções com uma determinada postura física, uma organização espacial e corporal, mas na maior parte das vezes, os alunos não sabem de onde elas vêm.

Uma psicanalista de setenta anos descreve da seguinte maneira as sensações desagradáveis na sua perna, antes da sessão:

Minha perna parece que tem lanterninhas que estão prestes a acender. A perna está em alerta! Parece que tem espinhos da coroa de Cristo.

Depois da sessão, peço que ela perceba como sente a perna. A sua descrição é a seguinte:

A perna parece quente, uma mussarela esticada. Não está mais em alerta!

Esta aluna então se lembra dos tempos de infância passados numa fazenda. Havia um dia especial, muito lúdico, em que todos se reuniam para fazer mussarela. Passa a me explicar como se coloca água quente no queijo, para esticar e fazer a mussarela.

Não há como interpretar essas imagens, só podemos recebê-las. Será que foi o toque preciso do Rolfing o responsável por desmanchar a aderência da fáscia da perna dolorida? Ou foi a
7.

Existem duas vias de conexão entre cérebro e corpo: neural (nervos motores e sensoriais periféricos, que transportam sinais de todo o corpo para o cérebro e vice-versa) e sanguínea (sinais químicos são transportados através de hormônios, neurotransmissores e neuromodeladores). A complexidade desta conexão foi esquematizada por Damásio (2004): o mundo exterior traz os sinais exteroceptivos, através dos sentidos: tato, olfato, paladar, visão, audição. O mundo interior traz os sinais interoceptivos, tanto via corrente sanguínea quanto via sensação do meio interno, o que inclui dor, temperatura, emoção, vísceras, músculos, sistema músculo-esquelético e sistema vestibular. Já o cérebro atua em todas as partes do corpo através da transmissão em feixes nervosos pelos neurônios. 
relação com a terapeuta que acalmou o alerta das pequenas lâmpadas prestes a se acender? Só podemos entender que o que veio depois, a metáfora gastronômica, tranquilizou-a, evocando um tempo feliz: uma mussarela esticada na água quente dos tempos da infância, no espaço do ócio, na segurança da família. E a perna acalma, descontrai, ao calor do toque.

Um editor de livros verbaliza suas sensações corpóreas durante as sessões, ancorado em textos de livros em que está trabalhando:

A caixa torácica é como uma gaiola - prende um pássaro.

Amargo é o despertar para quem esteve tanto tempo em tão profundo sono imerso.

Não sabia o quanto minha alma estava vazia até que ela foi preenchida.

O editor de livros se explica: diz que se refere à própria memória, no caso, a memória do corpo, de como ao sentir maior liberdade para respirar, só agora se lembra de como é este respirar mais livre. Só ao lembrar, percebe que tinha se esquecido... Só um corpo que consegue respirar, pode perceber que tinha comprimido a respiração.

No depoimento de outra aluna, uma jovem atriz:

No Rolfing começamos a tentar \{fazer com\} que meu corpo unisse a parte de cima e a de baixo que atuavam separadamente. $\mathrm{O}$ esterno passou a derreter um pouco, penso que passei a usar o chão, percebi que havia algo entre os ossos, a musculatura, que eu poderia chamar de 'vontade', 'de afeto', 'de coração' - unindo as coisas muito internamente.

Este estudante de cinema escreve o que sentiu depois da sua primeira série de Rolfing:

Lembro que o primeiro desafio visível com o Rolfing era que me protegia, contorcia mãos e pés para dentro, numa busca fetal de proteção e isolamento. Não trocava com a terra. Suspendia-me. Foi a primeira grande tarefa. Conscientemente, no ônibus e na escola, conectar-me. Até hoje me pego evitando trocas, torcendo um pé ou outro.

\section{Considerações Finais}

Uma explicação para o surgimento destas imagens e emoções é que através do toque na fáscia, o terapeuta informa que é possível "articular na articulação", ou seja, a pessoa pode se articular e deixar de ser um bloco, ganhando plasticidade e diferenciação, criando espaços de relação, dentro e fora, consigo mesma e com o mundo. Esta sensação de si mesmo que é articulada, diferenciada e portanto autônoma, pode ser muito potente: não é preciso "ficar se segurando". 
Essa memória do corpo, esse conjunto de sistemas sensório-motores organizado pelo hábito, pela história de vida e pelas crenças do que é um bom alinhamento, acaba constituindo uma postura corporal. Essas impressões do mundo no corpo são registradas na musculatura tônica, organizando o que o pesquisador francês Hubert Godard (1994) chama de prémovimento. O pré-movimento determina o estado de tensão do corpo e define a qualidade e a cor específica de cada gesto humano. O pré-movimento age sobre a organização gravitacional, isto é, sobre a forma como o sujeito organiza sua postura para ficar em pé e responder à lei da gravidade. O sistema dos músculos gravitacionais, cuja ação escapa em grande parte à consciência e à vontade, é encarregado de assegurar nossa postura. É o pré-movimento, invisível, imperceptível para o próprio indivíduo, que acionará, simultaneamente, os níveis mecânicos e afetivos de sua organização. Os efeitos desse estado afetivo que concedem a cada gesto sua qualidade, cujo mecanismo compreendemos tão pouco, não podem ser comandados apenas pela intenção. Talvez a resposta esteja na compreensão de que é a memória, fruto do encontro do corpo com o mundo, que vai tramando a cada instante esse registro no próprio corpo. E na ação de reorganizar-se, a pessoa pode relembrar, compreender, processar: tecido e memória se enredam num outro sistema, mais fluido, mais articulado, onde, talvez, a dor possa se transformar em poesia. 
REFERÊNCIAS BIBLIOGRÁFICAS:

BERGSON, H. Memória e Vida. São Paulo: Martins Fontes, 2006. BERTHOZ, A. Le sens du Mouvement. Paris: Odile Jacob, 1996. La simplexitè. Paris: Odile Jacob, 2009.

DAMÁSIO, A. Em busca de Espinosa - prazer e dor na ciência dos sentimentos. São Paulo: Companhia das letras, 2004.

E o cérebro criou o homem. São Paulo:

Companhia das letras, 2011.

DEWEY, J. Arte como Experiência. Tradução de Vera Ribeiro. São Paulo: Martins Fontes, 2010.

FEITIS, R. Ida Rolffala sobre Rolfing e realidade física. São Paulo: Summus Editorial, 1994

GIBBS, R.; LENZ, P.; FRANCOZO, E. Metaphor is grounded in embodied experience. Journal of Pragmatics, 36, pp 1189-1210, 2004. Acessado em www.sciencedirect.com no dia 09/06/2012.

GIBSON, J. The senses considered as perceptual systems. Boston: Hougton-Mifflin, 1966.

GODARD, Hubert. Reading the Body in Dance - A Model. Rolf Lines, october 1994:36-41. Rolf Institute, 1994.

. Gesto e Percepção. In: SOTER, S; PEREIRA,

R. (orgs) Lições de Dança 3. Rio de Janeiro: Univercidade, 1995.

França, Paris, 2013.

JOHNSON, D. H. Bone, Breath \& Gesture: Practices of Embodiment. Berkeley: North Atlantic Books, 1995.

JOHNSON, M. The Meaning of the Body: aestetics of human understanding. Chicago: The University of Chicago Press, 2007.

LARROSA, J. Notas sobre a experiência e o saber de experiência. Revista Brasileira de Educação [online]. 2002, n.19, pp. 20-28. disponível em http://educa.fcc.org.br/pdf/rbedu/n19/n19a03.pdf acesso em 29 ago 2011.

LEONARDELLI, Patrícia. A memória como recriação do vivido: um estudo da história do conceito de memória aplicado às artes performativas na perspectiva do depoimento pessoal. Tese de doutorado. Universidade de São Paulo, 2008

MAITLAND, J. Spacious Body: Explorations in Somatic Ontology. Berkeley: North Atlantic Books, 1996.

ROLF, I. Rolfing: A Integração das Estruturas Humanas, trad. Marylene P. Michael. São Paulo: Livraria Martins Fontes Editora, 1990. 
ROLNIK, S. Olhar cego. Entrevista com Hubert Godard. Para a exposição "Lygia Clark, do objeto ao contecimento: projeto de ativação de 26 anos de experimentação corporal.” Paris, 21 de julho de 2004.

VARELA, F.; THOMPSON, E.; ROSCH, E. A mente incorporada: ciências cognitivas e experiência humana. São Paulo: Artmed, 1985. 